\title{
Long-Lasting Effects of BCG Vaccination on Both Heterologous Th1/Th17 Responses and Innate Trained Immunity
}

\author{
Johanneke Kleinnijenhuis ${ }^{a, b}$ Jessica Quintin ${ }^{a, b}$ Frank Preijers ${ }^{c}$ \\ Christine Stabell Benn ${ }^{\mathrm{e}}$ Leo A.B. Joosten ${ }^{\mathrm{a}, \mathrm{b}}$ Cor Jacobs ${ }^{\mathrm{a}, \mathrm{b}}$ \\ Joke van Loenhout $^{d}$ Ramnik J. Xavier, $g$ Peter Aaby ${ }^{\mathrm{e}}$ \\ Jos W.M. van der Meer ${ }^{a, b}$ Reinout van Crevel ${ }^{a, b}$ Mihai G. Netea ${ }^{a, b}$ \\ ${ }^{a}$ Department of Medicine, ${ }^{b}$ Nijmegen Institute for Infection, Inflammation and Immunity (N4i) and \\ 'Department of Laboratory Medicine, Laboratory of Hematology, Radboud University Nijmegen Medical Centre, \\ and d GGD, Nijmegen, The Netherlands; ${ }^{e}$ Research Center for Vitamins and Vaccines (CVIVA), Statens Serum Institut, \\ Copenhagen, Denmark; ${ }^{f}$ Center for Computational and Integrative Biology and Gastrointestinal Unit, Massachusetts \\ General Hospital, Harvard School of Medicine, Boston, Mass., and 9 Broad Institute of MIT and Harvard University, \\ Cambridge, Mass., USA
}

\section{Key Words}

Innate immunity $\cdot$ BCG vaccination · Trained immunity

\begin{abstract}
We have recently shown that BCG (Bacillus Calmette-Guérin) vaccination in healthy volunteers induces epigenetic reprogramming of monocytes, leading to increased cytokine production in response to nonrelated pathogens for up to 3 months after vaccination. This phenomenon was named 'trained immunity'. In the present study we assessed whether BCG was able to induce long-lasting effects on both trained immunity and heterologous T helper 1 (Th1) and Th17 immune responses 1 year after vaccination. The production of TNFa and IL-1 $\beta$ to mycobacteria or unrelated pathogens was higher after 2 weeks and 3 months postvaccination, but these effects were less pronounced 1 year after vaccination. However, monocytes recovered 1 year after vaccination had an increased expression of pattern recogni-
\end{abstract}

tion receptors such as CD14, Toll-like receptor 4 (TLR4) and mannose receptor, and this correlated with an increase in proinflammatory cytokine production after stimulation with the TLR4 ligand lipopolysaccharide. The heterologous production of Th1 (IFN- $\gamma$ ) and Th17 (IL-17 and IL-22) immune responses to nonmycobacterial stimulation remained strongly elevated even 1 year after BCG vaccination. In conclusion, BCG induces sustained changes in the immune system associated with a nonspecific response to infections both at the level of innate trained immunity and at the level of heterologous Th1/Th17 responses.

(c) 2013 S. Karger AG, Basel

\section{Introduction}

Nonspecific beneficial effects of BCG (Bacillus Calmette-Guérin) have been described for many decades. Soon after its introduction in the 1920s, epidemiological

\section{KARGER}

E-Mail karger@karger.com

www.karger.com/jin
(C) 2013 S. Karger AG, Basel

$1662-811 X / 13 / 0062-0152 \$ 38.00 / 0$
Dr. Mihai G. Netea

Department of Medicine (463), Radboud University Nijmegen Medical Centre Geert Grooteplein Zuid 8

NL-6525 GA Nijmegen (The Netherlands)

E-Mail m.netea@ aig.umcn.nl 
studies surprisingly demonstrated that BCG protects against infant mortality independent of its effect on tuberculosis (TB) [1-5]. Recent studies supported these findings and suggested a reduction of the burden of infections other than TB [6-10]. For example, BCG decreased by half the neonatal mortality of children in several recent trials in West Africa $[8,9,11-14]$, while in a case-control study in Brazil, BCG reduced the risk of death from pneumonia by $50 \%$ in children less than 1 year of age [7]. In light of these data, the question arises as to which mechanisms mediate these nonspecific immune effects of BCG, and how long do they last?

Two possible immunological mechanisms have been proposed to explain the nonspecific beneficial effects of vaccination. The first such mechanism is heterologous immunity, in which cross-protection is mediated by heterologous $\mathrm{T}$ cell memory responses [15]. However, heterologous immunity needs at least a couple of weeks to develop, and it is thus highly unlikely to be responsible for the very rapid effects observed on perinatal immunity [14]. A second mechanism of protection has been recently proposed in the form of epigenetic reprogramming of immune cells, a phenomenon conferring nonspecific immune memory to innate immune responses and termed 'trained immunity' [16]. Many species of organisms lacking adaptive immunity, such as plants [17] or insects [18, 19], manifest robust immune memory after previous exposure to infections or certain microbial components, and adaptive features of innate immunity have also been demonstrated in mice devoid of functional adaptive immune responses [20, 21]. Prominent microbial components that are able to potentiate the effector function of innate immune cells and protect against infections are mycobacterial stimuli such as BCG, complete Freund's adjuvant and muramyl dipeptide [22-25]. Recently, we have shown that BCG vaccination in healthy volunteers led to NOD2-dependent epigenetic reprogramming of monocytes, which resulted in an increased expression of cellular receptors on the monocytes, accompanied by higher cytokine production in response to nonrelated pathogens [26]. This newly described mechanism might represent the explanation for the rapid nonspecific protective effects induced by BCG vaccination. However, it is not known how long trained immunity and/or heterologous immunity persist after BCG vaccination. Therefore, in the present study we investigated the long-term nonspecific effects of BCG vaccination in healthy volunteers by assessing the responses of both innate and adaptive immune cells to nonmycobacterial stimulation in a period extending up until 1 year after the vaccination.

Persistent Immune Effect of BCG

Vaccination

\section{Materials and Methods}

\section{Subjects}

Individuals (age range 20-36 years) scheduled to receive a BCG vaccination at the public health service because of travel to or work in TB-endemic countries were asked to participate in this trial. Twenty healthy individuals were included between August and November 2010. Blood was drawn before, and 2 weeks, 3 months and 1 year after the BCG vaccination. Two participants were lost to follow-up after 3 months. The study was approved by the Arnhem-Nijmegen Ethical Committee.

\section{PBMC Stimulation Assays}

For the PBMC stimulation assays the mononuclear cell fraction was isolated by density centrifugation from blood diluted 1:1 in pyrogen-free saline over Ficoll-Paque (Pharmacia Biotech, Uppsala, Sweden). Cells were washed twice in saline and resuspended in culture medium (RPMI, Invitrogen, Carlsbad., Calif., USA) supplemented with gentamicin $10 \mu \mathrm{g} / \mathrm{ml}$, L-glutamine $10 \mathrm{mM}$ and pyruvate $10 \mathrm{~mm}$. Cells were counted in a Coulter counter (Coulter Electronics) and the number was adjusted to $5 \times 10^{6}$ cells $/ \mathrm{ml}$. A total of $5 \times 10^{5}$ mononuclear cells in a $100-\mu$ l volume was added to round-bottomed 96-well plates (Greiner) with RPMI or with sonicated Mycobacterium tuberculosis (MTB) H37Rv $(1 \mu \mathrm{g} / \mathrm{ml}$ end protein concentration), heat-killed Candida albicans $\left(1 \times 10^{6} \mathrm{mi}-\right.$ croorganisms/ml, strain UC820), Staphylococcus aureus $\left(1 \times 10^{6}\right.$ microorganisms/ml, clinical isolate) or Escherichia coli lipopolysaccharide (LPS; $1 \mathrm{ng} / \mathrm{ml}$; Sigma-Aldrich, St. Louis, Mo., USA). After $24,48 \mathrm{~h}$ or 7 days supernatants were stored at $-20^{\circ} \mathrm{C}$. Cytokine concentrations were assessed in the supernatants using enzyme-linked immunosorbent assay (ELISA).

\section{Cytokine Measurements}

Circulating IFN- $\gamma$, IL-17 and IL-22 were measured in plasma with Sanquin Pelikine ELISA kits (IFN- $\gamma$ ) or R\&D Quantikine ELISA kits (IL-17 and IL-22; R\&D Systems, Minneapolis, Minn., USA), respectively, following the description of the manufacturer. Cytokine measurements of TNFa, IL-1 $\beta$, IFN- $\gamma$, IL-17 and IL-22 after PBMC stimulation were performed in the supernatants using commercial ELISA kits from R\&D Systems (TNFa, IL-1 $\beta$, IL-17 and IL-22) or Sanquin (IFN- $\gamma$; Amsterdam, The Netherlands). In a small proportion of baseline samples in which cytokine concentrations were beyond the detection limit, these outliers were excluded from the analysis.

\section{FACS Analysis}

Cells were phenotypically analyzed by ten-color and five-color flow cytometry using a Coulter Navios and Coulter Cytomics FC 500, respectively (Beckman Coulter, Fullerton, Fla., USA) and evaluated using Kaluza 1.1 software (Beckman Coulter). In order to guarantee reliable results the flow cytometry was calibrated with flow set pro beads (Beckman Coulter). Cells were washed in PBS with $1 \%$ bovine serum albumin before being labeled with fluorochrome-conjugated mAbs. After incubation for $30 \mathrm{~min}$ at $4^{\circ} \mathrm{C}$ in the dark, cells were washed twice to remove unbound antibodies and analyzed. For cell surface staining, the following mAbs were used: CD3-PECy7 (737657), CD4-PB (A82789), CD8-APC-A700 (A66332), CD45-PO (A96416), CD11b-PE (IM25814), CD14ECD (IM2707U), CD45-PC7 (IM3548; all from Beckman Coulter Corporation), CD284-PE (TLR4; 312806) and CD206-PE (321106; 


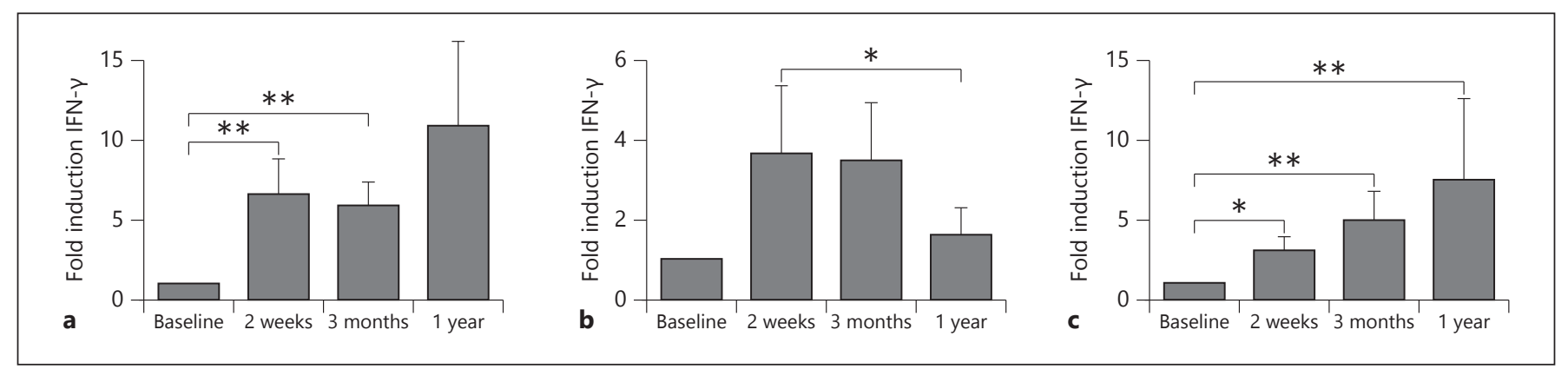

Fig. 1. BCG vaccination increased the heterologous Th1 responses. PBMCs isolated from 18 volunteers before and after ( 2 weeks, 3 months and 1 year) vaccination were stimulated in vitro with

both form Biolegend), CD16-FITC (335035) and CD282-APC (TLR2; 558319; both from BD biosciences) and dectin-1-APC (FAB1859A; R\&D Systems).

\section{Statistical Analysis}

Differences were analyzed using the Wilcoxon signed-rank test or Friedman test for paired samples. $\mathrm{p}<0.05$ was considered statistically significant. Unless otherwise stated, data are shown as cumulative results of data obtained in all volunteers (means + SEM).

\section{Results}

The Effect of BCG Vaccination on Heterologous Th1 and Th17 Responses

FACS analyses of T cell subpopulations did not show major shifts in CD4 and CD8 lymphocytes (online suppl. fig. 1; for all online suppl. material, see www.karger.com/ doi/10.1159/000355628). Circulating concentrations of the T cell-derived cytokines IFN- $\gamma$, IL-17 and IL-22 were below the detection limit at all time points (data not shown). In contrast, 2 weeks and 3 months after BCG vaccination, IFN- $\gamma$ production induced by $M T B$ was 7 -fold higher than the production before vaccination, as also reported previously [26]. Interestingly, this effect remained present for at least 1 year (fig. 1a). A similar increase in cytokine production after 2 weeks and 3 months was observed when cells were stimulated with unrelated pathogens (C. albicans or S. aureus; fig. 1b, c). The increased production persisted until 1 year after vaccination in the case of $S$. aureus, while it largely retuned to prevaccination levels after C. albicans stimulation.

In addition to its effects on Th1 responses, we sought to investigate the effect of $\mathrm{BCG}$ vaccination on the production of Th17-derived cytokines, namely IL-17 and IL22. MTB-stimulated IL-17 production was significantly sonicated MTB (a), heat-killed C. albicans yeast (b) and S. aureus (c). IFN- $\gamma$ production was assessed in the supernatants by ELISA. ${ }^{*} \mathrm{p}<0.05{ }^{* *} \mathrm{p}<0.01$.

higher in cells retrieved after BCG vaccination (fig. 2a). Moreover, this effect was independent of the stimulating pathogen, as a persistently increased IL-17 production was also observed upon stimulation with $C$. albicans (fig. 2b) and S. aureus (fig. 2c). The increased heterologous Th17 immunity was also reflected by the potentiated IL-22 production after BCG vaccination. This was apparent after stimulation of cells with MTB, C. albicans or $S$. aureus (fig. 2d-f).

\section{The Effect of BCG Vaccination on Trained Immunity}

Previously, we reported that BCG affected production of proinflammatory cytokines produced by monocytes, a prototypic innate immune cell population [26]. While TNF $\alpha$ and IL-1 $\beta$ production was higher 2 weeks and 3 months after vaccination, it largely returned to normal 1 year after BCG vaccination. This waning effect on TNFa and IL- $1 \beta$ release was observed upon stimulation of the cells with $M T B$, as well as with the nonrelated pathogen C. albicans (fig. $3 \mathrm{a}, \mathrm{b}$ ) or S. aureus (not shown). Similar data were obtained on IL- $1 \beta$ production (data not shown). However, LPS-induced TNF $\alpha$ (fig. 3c) and IL-1 $\beta$ (fig. 3d) production 1 year after vaccination remained significantly higher compared to prevaccination levels.

\section{The Effect of BCG Vaccination on Receptor Expression} on Monocytes

The expression of several pattern recognition receptors and activation markers on monocytes showed a sustained rise in expression over time. Figure 4 presents mean fluorescent indexes (MFI) of either markers of activity of monocytes (CD14 and CD11b; fig. 4a, b), Tolllike receptor 4 (TLR4) and TLR2 (fig. 4c, d), and C-type lectins (mannose receptor, $\mathrm{MR}$, and dectin-1; fig. 4e, f). The increase in MFI was receptor specific, as not all TLRs 


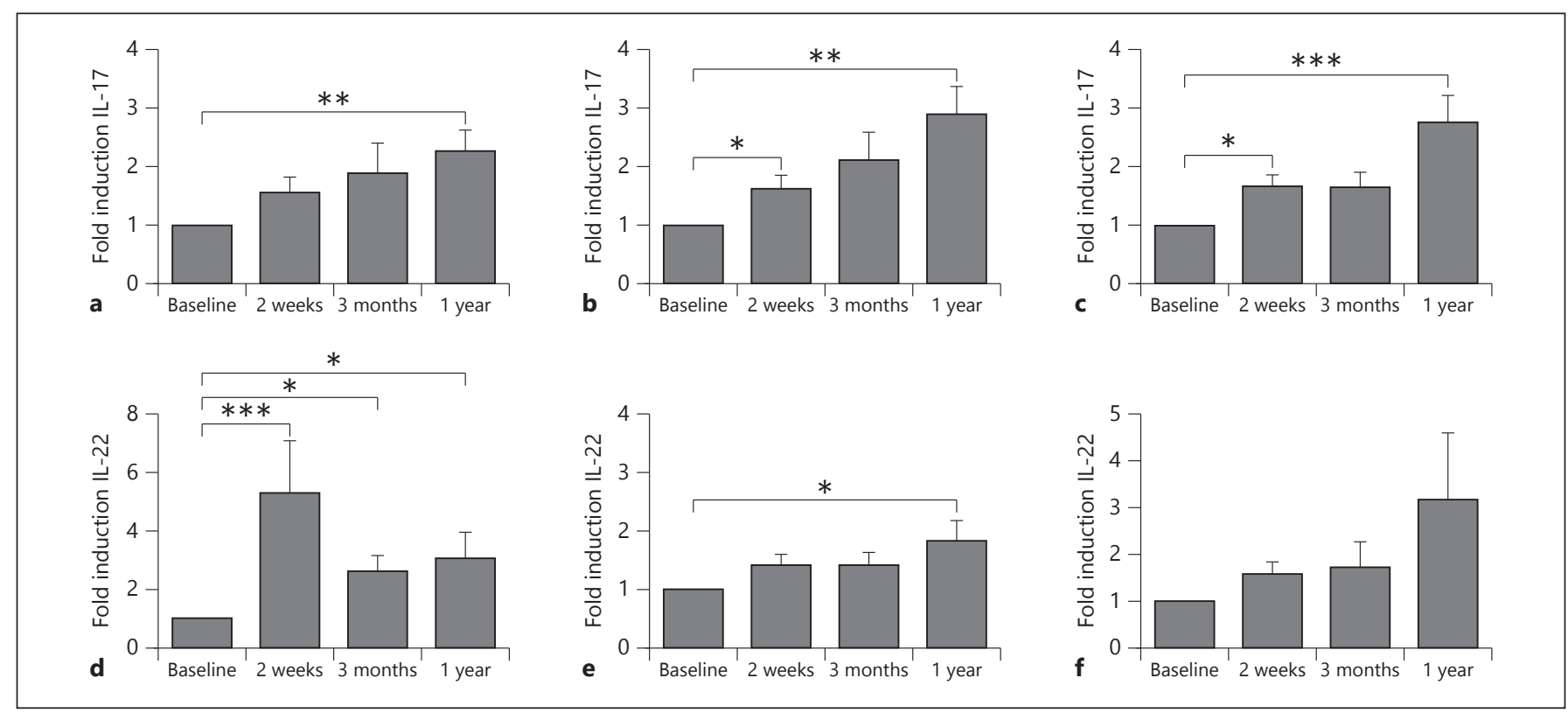

Fig. 2. BCG induces long-lasting heterologous Th17 responses. PBMCs isolated from 18 volunteers before and after (2 weeks, 3 months and 1 year) vaccination were stimulated in vitro with sonicated MTB (a, d), heat-killed C. albicans yeast (b, e) and $S$. aureus (c, f). IL-17 (a-c) and IL-22 (d-f) production was assessed by ELISA in the supernatants. ${ }^{*} \mathrm{p}<0.05 ;{ }^{* *} \mathrm{p}<0.01$; $^{* * *} \mathrm{p}<0.005$.
Fig. 3. Effect of BCG on innate immune cytokines. PBMCs isolated from 18 volunteers before and after ( 2 weeks, 3 months and 1 year) vaccination were stimulated in vitro with sonicated $M T B(\mathbf{a})$, heat-killed C. albicans yeast (b) and LPS (c, d). TNFa $(\mathbf{a}-\mathbf{c})$ and IL-1 $\beta$ (d) production was assessed by ELISA in the supernatants. ${ }^{*} \mathrm{p}<$ $0.05 ;{ }^{* *} \mathrm{p}<0.01$.

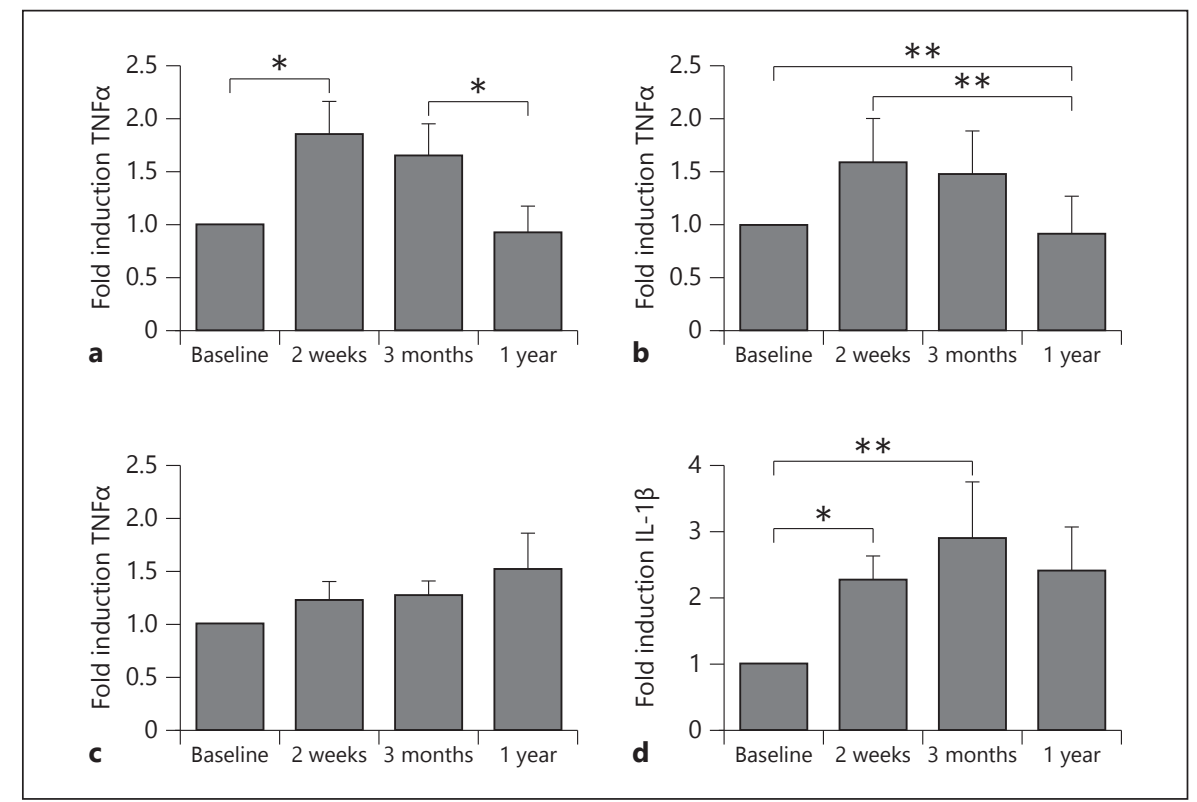

or C-type lectins were influenced by the vaccination. The activity markers CD14 and CD11b showed persistent higher levels of expression on monocytes that lasted for at least 1 year. Also, TLR4 and MR expression on monocytes were increased after BCG vaccination 1 year after vaccina- tion. No effect was seen on the expression of TLR2 or dectin-1 (fig. 4d, f). Online supplementary figure 2 shows the gating strategy for monocytes used in figure 4 . In addition, online supplementary figure 3 presents representative histograms of all the receptors shown in figure 4 . 


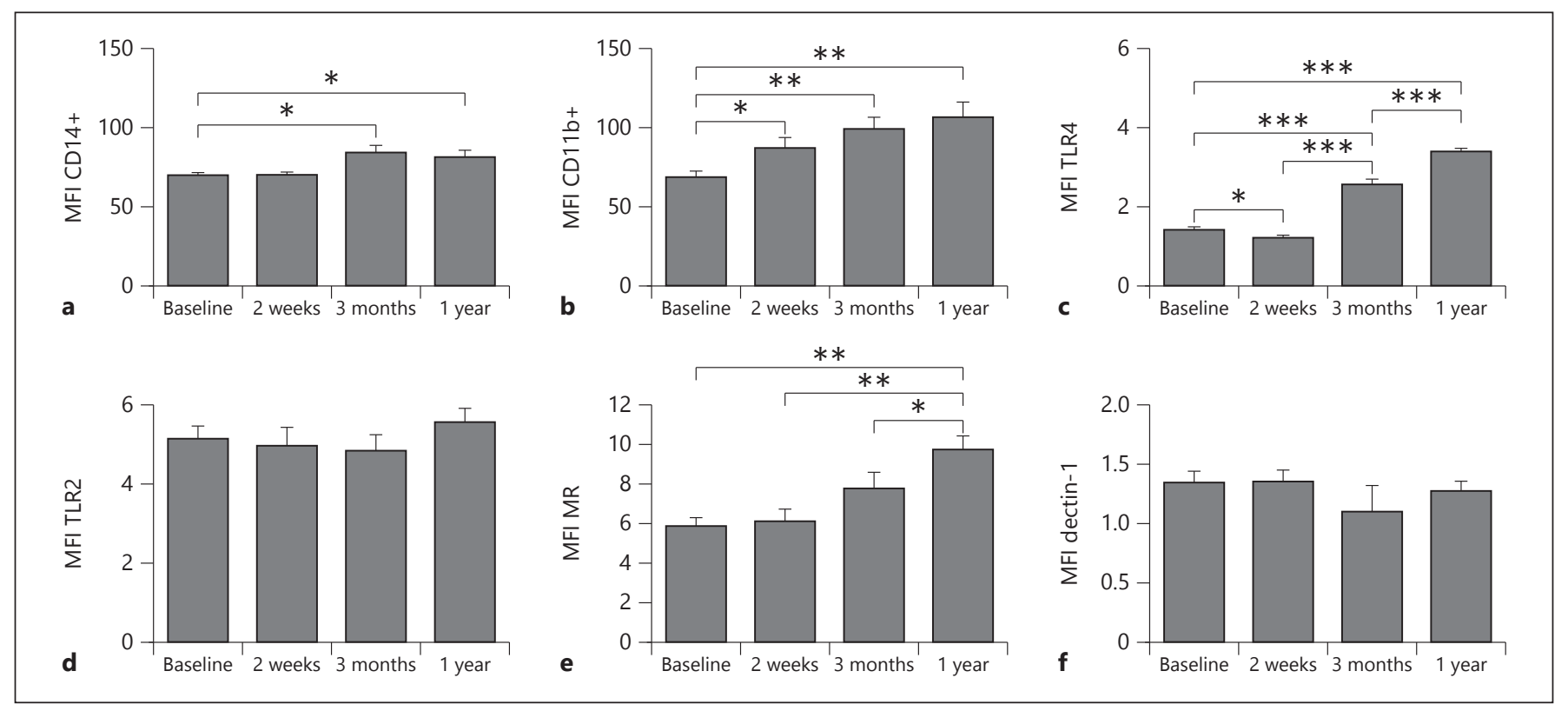

Fig. 4. BCG alters the phenotype of circulating monocytes in healthy volunteers. Average surface expression levels of activation markers CD14+ (a) and CD11b (b), TLR4 (c) and TLR2 (d), and
C-type lectin receptors MR (e) and dectin-1 (f) within the CD14+ monocytes population isolated from 18 volunteers before and after BCG vaccination. * $\mathrm{p}<0.05$ * $^{* *} \mathrm{p}<0.01$; $^{* * *} \mathrm{p}<0.005$.

\section{Discussion}

BCG has beneficial effects on infections other than TB, yet the immunological mechanisms responsible for these effects remain obscure. Recently, two immunological mechanisms have been suggested to mediate these effects: the short-time effects are most likely mediated by epigenetic reprogramming of innate immune cells, a process called 'trained immunity' [26], while long-term effects may be mediated by heterologous Th1/Th17 immunity [15], possibly in combination with residual trained immunity effects. In the present study we show that BCG vaccination induces nonspecific potentiation effects of both innate trained immunity and heterologous Thelper responses that are clearly present for at least 1 year after vaccination.

The long-term effects after BCG vaccination are most prominent on heterologous Th1 and Th17 responses. An explanation for this could be the process of 'cross-protection' described 5 decades ago [27], or termed later as 'heterologous immunity' $[15,28]$. The classical form of crossprotection is mediated by lymphocytes that release IFN- $\gamma$ after stimulation with a first-encountered pathogen and subsequently activate bystander macrophages, generating a state of temporary heightened innate immunity against a secondary infection, which wanes rapidly once the primary pathogen is eliminated [29]. The second form is long-lived and therefore maybe more comparable with our findings: Berg et al. [30] described that both effector and memory CD8+ cells have the potential to secrete IFN- $\gamma$ in response to IL-12 and IL-18 in the absence of a related antigen. The IL- 12 and IL- 18 are produced in the initial stages of a secondary infection. One additional possible explanation can be epitope sharing as described previously, although this is unlikely to play a major role for explaining the increased responses to C. albicans or $S$. aureus after BCG vaccination.

One could speculate that the increased reactivity of Th17 cells occurs in a similar fashion. The general principle of the induction of Th17 responses is similar to that of Th 1 immunity, with the difference that IL- $1 \beta$ and IL-23 (rather than IL-12 and IL-18) are the cytokines responsible for Th17 differentiation. The increased expression of pattern recognition receptors known to induce Th17 responses such as MR [31], and proinflammatory cytokines such as IL-1 $\beta$ [32], may at least partly account for the induction of heterologous Th17 immunity. The increase in these typical innate immune responses during the induction of trained immunity could thus contribute to heterologous $\mathrm{T}$ helper responses, but this direct relationship remains to be formally demonstrated by future studies. In addition, one may also speculate regarding potential deleterious effects of BCG-induced heterologous 
immunity during autoimmune processes. An important difference between BCG vaccination and autoimmune disorders is that while autoimmunity induces spontaneous IL-17 production with autoimmune tissue damage, BCG vaccination only induces a primed status of the cells to respond more strongly to secondary microbial stimulation. Without stimulation, no higher production of these cytokines was seen. In line with this, one study even reported a beneficial effect of BCG vaccination on type 1 diabetes mellitus [33], and beneficial effects on asthma and allergies have also been reported [34].

In addition to the effects on heterologous immunity, BCG vaccination also shows long-term effects on innate trained immunity. This is revealed by the persistent increase in LPS-mediated proinflammatory cytokine production, and expression of pattern recognition receptors and monocyte activation markers. One may hypothesize that these two effects are related, as it is mainly the expression of the LPS receptors TLR4 and CD14 [35], which remained high 1 year after BCG, that are responsible for enhanced cytokine responses after LPS stimulation. In contrast, the expression of other pattern recognition receptors such as dectin-1 and TLR2 was not affected by BCG vaccination. While alterations in S. aureus and C. albicansmediated cytokine production were clearly present 2 weeks and 3 months after vaccination, these effects waned after 1 year. This suggests that at least for some innate immune pathways, the epigenetic reprogramming responsible for the trained immunity effects [26] are relatively short lived and are present for months rather than years.
In conclusion, in the present study we have characterized the long-term nonspecific immunological effects of BCG vaccination. We have previously shown that innate immunity has adaptive features, termed trained immunity [16]. While a maximum duration of trained immunity effects of 3 months has been reported to date [26], in the present study we have shown that the nonspecific training effects of BCG vaccination on receptor expression and LPS-induced proinflammatory cytokines is long-standing and present for at least 1 year. In addition, strongly increased heterologous Th1 and Th17 responses have been observed 1 year after the vaccination. These double effects of BCG vaccination on both trained immunity and heterologous $\mathrm{T}$ cell responses provide a likely explanation for both the short- and long-term nonspecific effects of BCG, which have been known for decades and may have important implications for vaccine development and healthcare policy.

\section{Acknowledgments}

J.Q. and M.G.N. were supported by a Vici Grant of the Netherlands Organization for Scientific Research (to M.G.N.). R.V.C. was supported by a Vidi Grant of the Netherlands Organization for Scientific Research. R.J.X. was supported by grants (AI 062773, DK 043351, DK 83756) from the US National Institutes of Health and the Helmsley Trust. CVIVA is supported by the Danish National Research Foundation (DNRF108). CSB was funded by an ERC Starting Grant (through grant ERC-2009-StG-243149).

\section{References}

1 Levine MI, Sackett MF: Results of BCG immunization in New York City. Am Rev Tuberc 1946;53:517-532.

2 Aronson JD: Protective vaccination against tuberculosis, with special reference to BCG vaccine. Minn Med 1948;31:1336.

- 3 Ferguson RG, Simes AB: BCG vaccination of Indian infants in Saskatchewan. Tubercle 1949;30:5-11.

4 Rosenthal SR, Loewinsohn E, Graham ML, Liveright D, Thorne MG, Johnson V: BCG vaccination in tuberculous households. Am Rev Respir Dis 1961;84:690-704.

5 Naeslund C: Expérience de vaccination par le BCG dans la province du Norrbotten (Suède). Rev Tuberc 1931;12:617-636.

6 Velema JP, Alihonou EM, Gandaho T, Hounye FH: Childhood mortality among users and non-users of primary health care in a rural West African community. Int J Epidemiol 1991;20:474-479.

Persistent Immune Effect of BCG

Vaccination
Niobey FM, Duchiade MP, Vasconcelos AG, de Carvalho ML, Leal MC, Valente JG: Risk factors for death caused by pneumonia in children younger than 1 year old in a metropolitan region of southeastern Brazil: a casecontrol study (in Portuguese). Rev Saude Publica 1992;26:229-238.

-8 Kristensen I, Aaby P, Jensen H: Routine vaccinations and child survival: follow-up study in Guinea-Bissau, West Africa. BMJ 2000; 321:1435-1438.

\$9 Garly ML, Martins CL, Bale C, Balde MA, Hedegaard KL, Gustafson P, Lisse IM, Whittle HC, Aaby P: BCG scar and positive tuberculin reaction associated with reduced child mortality in West Africa: a non-specific beneficial effect of BCG? Vaccine 2003;21:27822790.

10 Vaugelade J, Pinchinat S, Guiella G, Elguero E, Simondon F: Non-specific effects of vaccination on child survival: prospective co- hort study in Burkina Faso. BMJ 2004;329: 1309.

11 Roth A, Garly ML, Jensen H, Nielsen J, Aaby $P$ : Bacillus calmette-guerin vaccination and infant mortality. Expert Rev Vaccines 2006;5: 277-293.

12 Stensballe LG, Nante E, Jensen IP, Kofoed PE, Poulsen A, Jensen H, Newport M, Marchant A, Aaby P: Acute lower respiratory tract infections and respiratory syncytial virus in infants in Guinea-Bissau: a beneficial effect of BCG vaccination for girls community based casecontrol study. Vaccine 2005;23:1251-1257.

13 Aaby P, Roth A, Ravn H, Napirna BM, Rodrigues A, Lisse IM, Stensballe L, Diness BR, Lausch KR, Lund N, Biering-Sorensen S, Whittle H, Benn CS: Randomized trial of BCG vaccination at birth to low-birth-weight children: beneficial nonspecific effects in the neonatal period? J Infect Dis 2011;204:245252 . 
14 Biering-Sorensen S, Aaby P, Napirna BM, Roth A, Ravn H, Rodrigues A, Whittle H, Benn CS: Small randomized trial among lowbirth-weight children receiving bacillus Calmette-Guérin vaccination at first health center contact. Pediatr Infect Dis J 2012;31: 306-308.

15 Welsh RM, Selin LK: No one is naive: the significance of heterologous T-cell immunity. Nat Rev Immunol 2002;2:417-426.

-16 Netea MG, Quintin J, van der Meer JW: Trained immunity: a memory for innate host defense. Cell Host Microbe 2011;9:355-361.

17 Durrant WE, Dong X: Systemic acquired resistance. Ann Rev Phytopathol 2004;42:185209.

18 Pham LN, Dionne MS, Shirasu-Hiza M, Schneider DS: A specific primed immune response in Drosophila is dependent on phagocytes. PLoS Pathog 2007;3:e26.

19 Rodrigues J, Brayner FA, Alves LC, Dixit R, Barillas-Mury C: Hemocyte differentiation mediates innate immune memory in Anopheles gambiae mosquitoes. Science 2010;329: 1353-1355.

20 Sun JC, Beilke JN, Lanier LL: Adaptive immune features of natural killer cells. Nature 2009;457:557-561.

-21 Quintin J, Saeed S, Martens JH, GiamarellosBourboulis EJ, Ifrim DC, Logie C, Jacobs L, Jansen T, Kullberg BJ, Wijmenga C, Joosten LA, Xavier RJ, van der Meer JW, Stunnenberg HG, Netea MG: Candida albicans infection affords protection against reinfection via functional reprogramming of monocytes. Cell Host Microbe 2012;12:223-232.
Gorhe DS: Inhibition of multiplication of foot and mouth disease virus in adult mice pretreated with Freund's complete adjuvant. Nature 1967;216:1242-1244.

23 Chedid L, Parant M, Parant F, Lefrancher P, Choay J, Lederer E: Enhancement of nonspecific immunity to klebsiella pneumoniae infection by a synthetic immunoadjuvant $(\mathrm{N}$ acetylmuramyl-L-alanyl-D-isoglutamine) and several analogs. Proc Natl Acad Sci USA 1977; 74:2089-2093.

24 van 't Wout JW, Poell R, van FR: The role of BCG/PPD-activated macrophages in resistance against systemic candidiasis in mice. Scand J Immunol 1992;36:713-719.

25 Sakuma T, Suenaga T, Yoshida I, Azuma M: Mechanisms of enhanced resistance of $\mathrm{Myco}$ bacterium bovis BCG-treated mice to ectromelia virus infection. Infect Immun 1983;42: 567-573.

26 Kleinnijenhuis J, Quintin J, Preijers F, Joosten LA, Ifrim DC, Saeed S, Jacobs C, van Loenhout J, de Jong D, Stunnenberg HG, Xavier RJ, van der Meer JW, van Crevel R, Netea MG: Bacille Calmette-Guérin induces NOD2-dependent nonspecific protection from reinfection via epigenetic reprogramming of monocytes. Proc Natl Acad Sci USA 2012;109: 17537-17542.

27 Mackaness GB: The immunological basis of acquired cellular resistance. J Exp Med 1964; 120:105-120.

28 Selin LK, Varga SM, Wong IC, Welsh RM: Protective heterologous antiviral immunity and enhanced immunopathogenesis mediated by memory T cell populations. J Exp Med 1998;188:1705-1715.
29 Mackaness GB: The influence of immunologically committed lymphoid cells on macrophage activity in vivo. J Exp Med 1969;129: 973-992.

30 Berg RE, Crossley E, Murray S, Forman J: Memory CD8+ $\mathrm{T}$ cells provide innate immune protection against listeria monocytogenes in the absence of cognate antigen. J Exp Med 2003;198:1583-1593.

31 van de Veerdonk FL, Marijnissen RJ, Kullberg BJ, Koenen HJ, Cheng SC, Joosten I, van den Berg WB, Williams DL, van der Meer JW, Joosten LA, Netea MG: The macrophage mannose receptor induces IL-17 in response to Candida albicans. Cell Host Microbe 2009; 5:329-340.

32 Kryczek I, Wei S, Vatan L, Escara-Wilke J, Szeliga W, Keller ET, Zou W: Cutting edge: opposite effects of IL- 1 and IL-2 on the regulation of IL-17+ T cell pool IL-1 subverts IL2-mediated suppression. J Immunol 2007; 179:1423-1426.

33 Faustman DL, Wang L, Okubo Y, Burger D, Ban L, Man G, Zheng H, Schoenfeld D, Pompei R, Avruch J, Nathan DM: Proof-of-concept, randomized, controlled clinical trial of Bacillus-Calmette-Guerin for treatment of longterm type 1 diabetes. PLoS One 2012;7:e41756.

34 Rousseau MC, Parent ME, St-Pierre Y: Potential health effects from non-specific stimulation of the immune function in early age: the example of BCG vaccination. Pediatr Allergy Immunol 2008; 19:438-448.

35 Akashi-Takamura S, Miyake K: TLR accessory molecules. Curr Opin Immunol 2008;20: 420-425. 